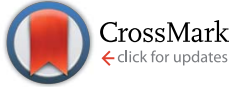

Cite this: RSC Adv., 2017, 7, 2019

Received 28th October 2016 Accepted 6th December 2016

DOI: 10.1039/c6ra25951k

www.rsc.org/advances

\title{
Synthesis, structure and magnetic properties of $\left(\mathrm{Eu}_{1-x} \mathrm{Mn}_{x}\right) \mathrm{MnO}_{3-\delta} \dagger$
}

\author{
Jianming Deng, ${ }^{\text {b }}$ Aimei Yang, ${ }^{\mathrm{b}}$ M. A. Farid, ${ }^{\mathrm{a}}$ Hao Zhang, ${ }^{\mathrm{a}}$ Jian Li, ${ }^{\mathrm{a}}$ Hongxing Zhang, ${ }^{\mathrm{a}}$ \\ Guobao Li, ${ }^{\text {a }}$ Laijun Liu, ${ }^{* b}$ Junliang Sun ${ }^{a}$ and Jianhua Lin*a
}

The solid solution $\left(\mathrm{Eu}_{1-x} \mathrm{Mn}_{x}\right) \mathrm{MnO}_{3-\delta}(0 \leq x \leq 0.126)$ has been synthesized using a conventional solidstate method. Powder $X$-ray diffraction and selected area electron diffraction data reveal that all samples crystallize in the space group Pnma. Magnetic measurements indicate that the temperature of the paramagnetic to antiferromagnetic phase transition increases with an increase of $\mathrm{Mn}$ in the Eu sites. The neutron diffraction data for ${ }^{153} \mathrm{EuMnO}_{3}$ at $3 \mathrm{~K}$ confirmed that the magnetic structure of $\mathrm{EuMnO}_{3}$ at low temperature is a canted A-type antiferromagnetic structure with the magnetic space group Pnma1'.

\section{Introduction}

Studies of $\mathrm{LnMnO}_{3}(\mathrm{Ln}=\mathrm{Y}, \mathrm{Eu}, \mathrm{Gd}, \mathrm{Tb}, \mathrm{Dy}, \mathrm{Ho}, \mathrm{Er}, \mathrm{Tm}, \mathrm{Yb}, \mathrm{Lu})$ have been enhanced after the discovery of both magnetic and ferroelectric order (called multiferroics) in $\mathrm{TbMnO}_{3},{ }^{1} \mathrm{YMnO}_{3},{ }^{2}$ and $\mathrm{HoMnO}_{3} \cdot{ }^{3}$ Lots of studies have focused on the doping of $\mathrm{LnMnO}_{3}$ (ref. 4-10) at the Ln and/or Mn sites to find better multiferroics. Particularly, several reports indicate that Mn can be doped into the Ln site. ${ }^{\mathbf{1 1 - 1 7}}$ This may help us to understand that the properties of $\mathrm{LnMnO}_{3}$ reported in the literature can be different because the composition may be different. Therefore, it should be very useful to have a systematic study on the relationship between the properties and the composition of $\operatorname{Ln}_{1-x^{-}}$ $\mathrm{Mn}_{x} \mathrm{MnO}_{3}$. Although it is known that Mn can be doped into the Eu site of EuMnO${ }_{3}{ }^{18}$ detailed studies are fewer. In addition, our previous work ${ }^{15-17}$ has indicated that $\mathrm{Tb}_{1-x} \mathrm{Mn}_{\mathrm{y}} \mathrm{MnO}_{3}$ can show very interesting magnetic properties. Therefore, careful studies into the synthesis, structure and magnetic properties of $\mathrm{Mn}$ doped $\mathrm{EuMnO}_{3}$ are performed. The details are presented below.

\section{Experimental}

Samples with the nominal formula $\left(\mathrm{Eu}_{1-x} \mathrm{Mn}_{x}\right) \mathrm{MnO}_{3-\delta}(x=0$, $0.025,0.05,0.075,0.1,0.125$ and 0.15) (named M1, M2, M3, M4, M5, M6 and M7, respectively) were synthesized using a traditional solid-state reaction from stoichiometric

${ }^{a}$ Beijing National Laboratory for Molecular Sciences, State Key Laboratory of Rare Earth Materials Chemistry and Applications, College of Chemistry and Molecular Engineering, Peking University, Beijing 100871, P. R. China. E-mail: liguobao@pku. edu.cn

${ }^{b}$ College of Materials Science and Engineering, Guilin University of Technology, Guilin 541004, China

$\dagger$ Electronic supplementary information (ESI) available. See DOI: 10.1039/c6ra25951k amounts of $\mathrm{Eu}_{2} \mathrm{O}_{3}$ (99.95\%) or ${ }^{153} \mathrm{Eu}_{2} \mathrm{O}_{3}$ (99.995\%), and $\mathrm{MnCO}_{3}$ (A.R.). Here the formula is noted as $\left(\mathrm{Eu}_{1-x} \mathrm{Mn}_{x}\right)$ $\mathrm{MnO}_{3-\delta}$ instead of $\left(\mathrm{Eu}_{1-x} \mathrm{Mn}_{x}\right) \mathrm{MnO}_{3}$ to highlight that the oxygen component is not exactly analyzed. Some oxygen vacancies may appear in the samples. The oven-dried reagents were mixed and homogenized through about thirty minutes of grinding with an agate mortar and a pestle. The mixtures were subjected to $6 \mathrm{~h}$ of calcination at $800{ }^{\circ} \mathrm{C}$. They were then pressed into pellets to undergo four $12 \mathrm{~h}$ heat treatments at $1200{ }^{\circ} \mathrm{C}$, followed by a furnace cooling every time with intermediate grinding. All the treatments were carried out under air. The weights of the samples were monitored before and after heat treatment. The maximum difference was about $4 \mathrm{mg}$ for the $6 \mathrm{~g}$ samples. Therefore, the final compositions of the samples were considered the same as the initial ones. Powder X-ray diffraction (PXRD) data were collected on a PANalytical X'Pert ${ }^{3}$ Powder diffractometer with $\mathrm{Cu} \mathrm{K} \alpha_{\alpha}\left(\lambda_{1}=\right.$ $0.15405 \mathrm{~nm}$ and $\lambda_{2}=0.15443 \mathrm{~nm}$ ) radiation (2 $\theta$ range: $5-120^{\circ}$ for $2 \mathrm{~h}$; step size: $0.0131^{\circ}$ ) at $40 \mathrm{kV}$ and $40 \mathrm{~mA}$ at room temperature. Neutron powder diffraction (NPD) data for ${ }^{153} \mathrm{EuMnO}_{3}$ were collected on the instrument Echidna at the OPAL reactor (Lucas Heights, Australia) at the Australian Nuclear Science and Technology Organization (ANSTO), at $\lambda=$ $1.62150 \AA$ A. The X-ray diffraction data were analyzed using GSAS software. ${ }^{19,20}$ The magnetic properties were investigated using a Cryogenic physical property measurement system (PPMS) from 2 to $300 \mathrm{~K}$. Selected area electron diffractions (SAED) were carried out on a JEM2100F, with a $200 \mathrm{kV}$ accelerating voltage. The X-ray photoelectron spectroscopy (XPS) patterns were obtained with a UK Kratos AxisUltra spectrometer with an $\mathrm{Al} \mathrm{K} \alpha \mathrm{X}$-ray source operating at $15 \mathrm{kV}$ and $15 \mathrm{~mA}$. The chamber pressure was less than $5.0 \times 10^{-9}$ torr. Electron binding energies were calibrated against $\mathrm{C} 1 \mathrm{~s}$ emission at $E_{\mathrm{b}}=284.8 \mathrm{eV}$. 


\section{Results and discussion}

Solid solution of $\left(\mathrm{Eu}_{1-x} \mathrm{Mn}_{x}\right) \mathrm{MnO}_{3-\delta}$

The X-ray diffraction patterns of the studied samples are shown in Fig. 1. The data for M1 to M6 are very similar, with the reflections moving systematically to a higher angle when more $\mathrm{Mn}$ is in the samples. These patterns agree well with that reported for $\mathrm{EuMnO}_{3}$ (ref. 21) in the space group Pnma, which indicates that the space group Pnma may be fitted to describe the structure of these samples. After considering that the true structure for a Perovskite compound is very complex, ${ }^{22-24}$ selected area electron diffraction (SAED) patterns of the above samples have been obtained and analyzed. The typical data are shown in Fig. 2, which confirm that the space group Pnma can be used to describe the structure of M1 to M6. Then the structure of $\mathrm{EuMnO}_{3}$ is used to refine the corresponding data, with the supposition that some Mn occupies Eu sites, using the Rietveld method using GSAS. Good refinement is obtained for all of the data with $R_{\mathrm{wp}} \leq 0.023$ and $R_{\mathrm{p}} \leq 0.013$ (the corresponding data is listed in Tables S1 and S2 in the ESI $\dagger$ ). Typical Rietveld plots are shown in Fig. 3. For M7, a small amount of $\mathrm{Mn}_{3} \mathrm{O}_{4}$ impurity was detected, which has been marked in Fig. 3d. Then a two phase model is used to refine the data for M7.

As shown in Fig. 4, with an increase in $\mathrm{Mn}$ in $\left(\mathrm{Eu}_{1-x} \mathrm{Mn}_{x}\right)$ $\mathrm{MnO}_{3-\delta}$, the lattice parameters $a$ and $c$ decrease, and $b$ increases, which agrees well with Vegard's law: ${ }^{25,26}$

$$
\begin{aligned}
& a_{\mathrm{O} x}=a_{\mathrm{O} 0}(1-x)+a_{\mathrm{O} 1} x \\
& b_{\mathrm{O} x}=b_{\mathrm{O} 0}(1-x)+b_{\mathrm{O} 1} x
\end{aligned}
$$

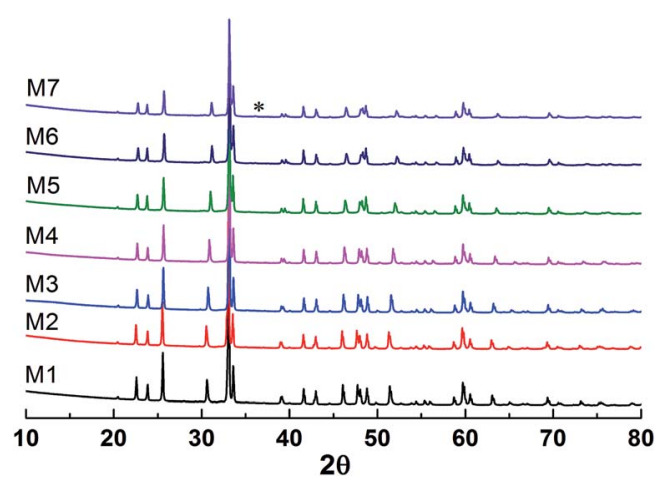

Fig. 1 Powder $X$-ray diffraction patterns of the samples with the nominal formula $\left(\mathrm{Eu}_{1-x} \mathrm{Mn}_{x}\right) \mathrm{MnO}_{3-\delta}$ * reflections from the impurity.
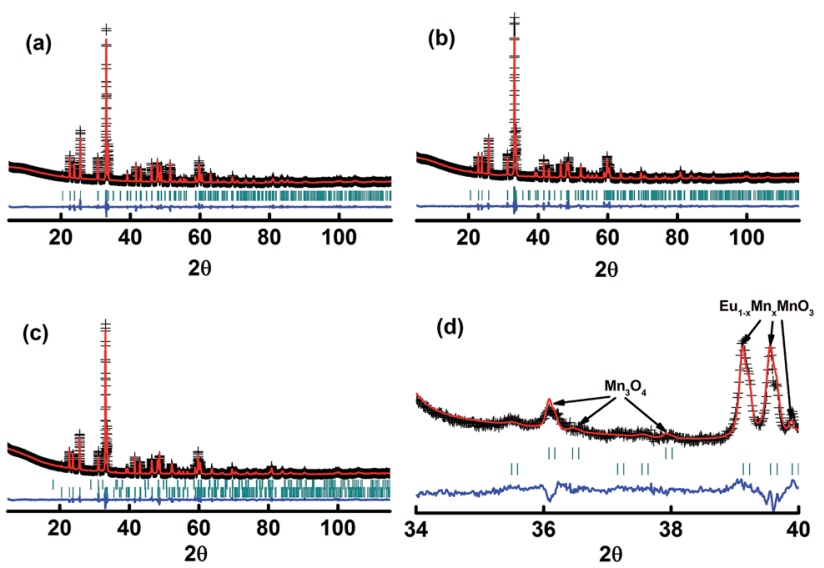

Fig. 3 Rietveld plots of the powder $\mathrm{X}$-ray diffraction patterns for the samples M1 (a), M6 (b), and M7 (c and d). The symbol "+" represents the observed value, the solid line represents the calculated value, the marks below the diffraction patterns are the calculated reflection positions, and the difference curve is shown at the bottom of the figure.

$$
c_{\mathrm{O} x}=c_{\mathrm{O} 0}(1-x)+c_{\mathrm{O} 1} x
$$

where $a_{\mathrm{O} x}\left(b_{\mathrm{O} x}, c_{\mathrm{O} x}\right), a_{\mathrm{O} 0}\left(b_{\mathrm{O} 0}, c_{\mathrm{O} 0}\right)$, and $a_{\mathrm{O} 1}\left(b_{\mathrm{O} 1}, c_{\mathrm{O} 1}\right)$ are the lattice parameters $a(b, c)$ of orthorhombic $\left(\mathrm{Eu}_{1-x} \mathrm{Mn}_{x}\right) \mathrm{MnO}_{3-\delta}$, pure orthorhombic EuMnO${ }_{3}$ and supposed orthorhombic $\mathrm{MnMnO}_{3}$. $x$ is the composition variable, given by $\mathrm{Mn} /(\mathrm{Eu}+\mathrm{Mn})$. Using the data shown in Fig. 4 and eqn (1)-(3), the maximum value for $x$ in the solid solution $\left(\mathrm{Eu}_{1-x} \mathrm{Mn}_{x}\right) \mathrm{MnO}_{3-\delta}$ is found to be 0.126 . That is, the range for the solid solution $\left(\mathrm{Eu}_{1-x} \mathrm{Mn}_{x}\right) \mathrm{MnO}_{3-\delta}$ is $0 \leq x \leq$ 0.126. The lattice parameters of the solid solution $\left(\mathrm{Eu}_{1-x} \mathrm{Mn}_{x}\right)$ $\mathrm{MnO}_{3-\delta}$ follow well the relationship $b / \sqrt{2}<c<a$, which indicates that the solid solution $\left(\mathrm{Eu}_{1-x} \mathrm{Mn}_{x}\right) \mathrm{MnO}_{3-\delta}$ belongs to an orthorhombic OI structure. ${ }^{27}$

\section{XPS data for $\left(\mathrm{Eu}_{1-x} \mathrm{Mn}_{x}\right) \mathrm{MnO}_{3-\delta}$}

In order to assess the oxidation states of $\mathrm{Eu}$ and $\mathrm{Mn}$ in the samples, XPS analysis has been performed. The corresponding data are shown in Fig. 5. The XPS spectra for Eu 3d in the samples M1 to M6 are almost the same. The two peaks at around 1135.6 and $1165.2 \mathrm{eV}$ are attributed to $\mathrm{Eu} 3 \mathrm{~d}_{5 / 2}$ and $\mathrm{Eu}$ $3 \mathrm{~d}_{3 / 2}$, which indicates that the valence state of $\mathrm{Eu}$ in the samples is $+3 .^{28,29}$ The XPS spectra of Mn 2p are also almost the same for all six samples, as shown in Fig. 5b. The corresponding Mn $2 \mathrm{p}_{3 / 2}$ peak is located at about $641.9 \mathrm{eV}$, which agrees well with the

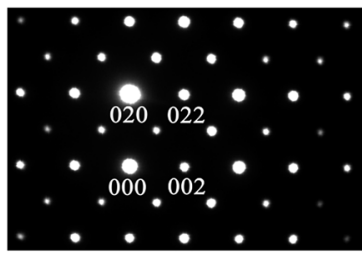

a [100]

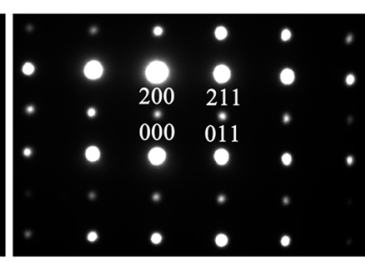

b $[01 \overline{1}]$

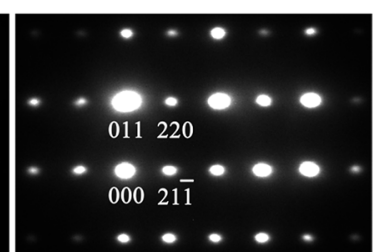

c [1]1]

Fig. 2 Selected area electron diffraction patterns of M5 along the [100], [011, and [111] directions in the space group Pnma. 

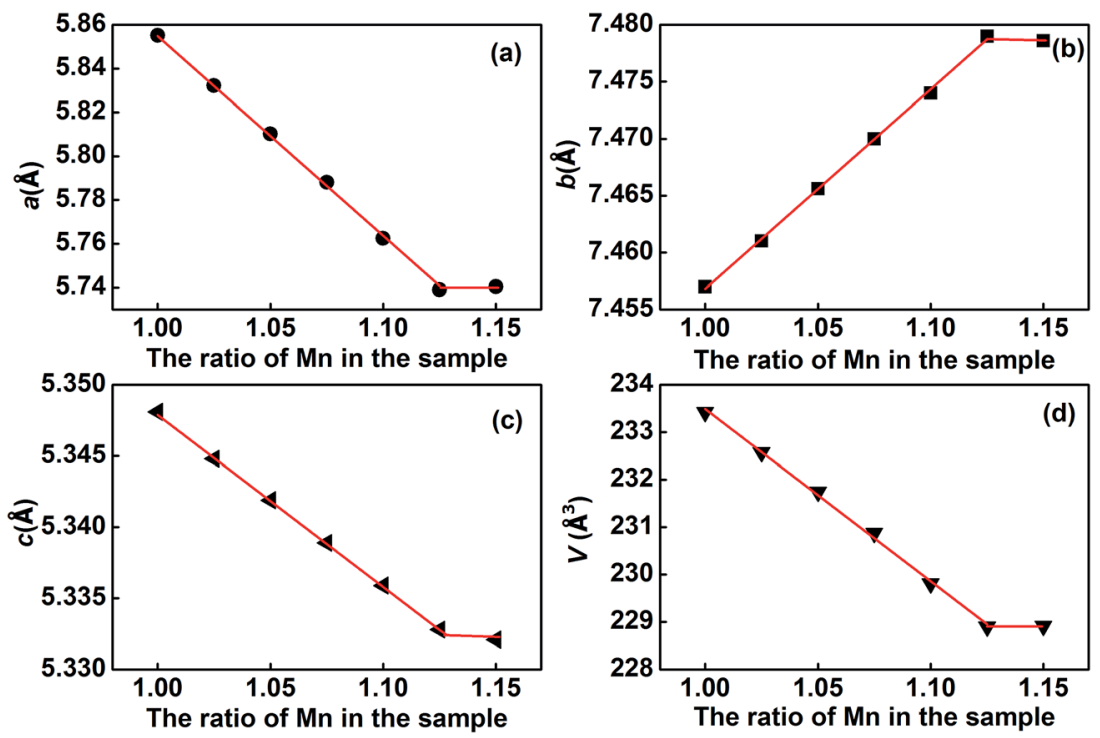

Fig. 4 Variation of the lattice parameters $a(a), b$ (b), c (c) and the volume of the unit cell $V(d)$ for the solid solution $\left(E u_{1-x} M_{x}\right) M n n O_{3-\delta}$.

binding energy of $\mathrm{Mn} 2 \mathrm{p}_{3 / 2}$ in $\alpha-\mathrm{Mn}_{2} \mathrm{O}_{3} \cdot{ }^{30,31}$ Thus, the valence state of $\mathrm{Mn}$ is +3 in the solid solution $\left(\mathrm{Eu}_{1-x} \mathrm{Mn}_{x}\right) \mathrm{MnO}_{3-\delta}$.

\section{Magnetic properties}

As reported previously, ${ }^{32}$ "negative magnetization" in the ZFC (zero field cooling) curve can be easily observed for M1 $\left(\mathrm{EuMnO}_{3}\right)$, which is attributed to the effect of a trapped negative field in the solenoid of a superconducting magnet. Two characteristic temperatures can be assigned to M1: the temperature where the ZFC and FC (field cooling) curves start to depart, which is attributed by us to the phase transition temperature from PM to AFM, noted as $T_{\mathrm{N} 1}$, which is $52 \mathrm{~K}$; and the peak temperature in the ZFC curves, which is attributed to the phase
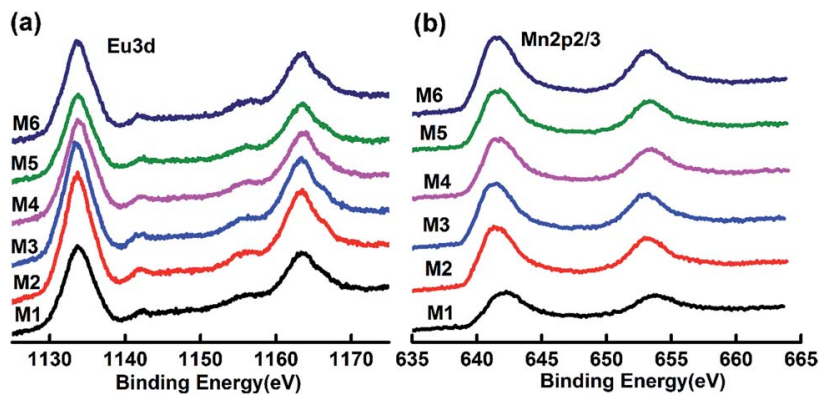

Fig. 5 XPS spectra of Eu $3 d_{5 / 2}$ (a) and Mn 2p $p_{3 / 2}$ (b) for M1 to M6.

Table 1 The $T_{\mathrm{N} 1}, T_{\mathrm{N} 2}$, Curie constant (C), $\theta, \mu_{\mathrm{cal}}$, and $\mu_{\mathrm{exp}}$ for $\mathrm{M} 1$ to $\mathrm{M} 6$

\begin{tabular}{lllllll}
\hline Sample & M1 & M2 & M3 & M4 & M5 & M6 \\
\hline$T_{\mathrm{N} 1}(\mathrm{~K})$ & 52 & 53 & 55 & 58 & 64 & 70 \\
$T_{\mathrm{N} 2}(\mathrm{~K})$ & 45 & 42 & 32 & 40 & 42 & 42 \\
$C\left(\mathrm{emu} \mathrm{mol}^{-1} \mathrm{~K}\right)$ & 4.87 & 5.10 & 5.18 & 5.21 & 5.24 & 5.25 \\
$\theta(\mathrm{K})$ & -84 & -54.0 & -48.6 & -36.1 & -19.6 & -21.9 \\
$\mu_{\text {cal }}\left(\mu_{\mathrm{B}}\right)$ & 5.96 & 5.99 & 6.02 & 6.04 & 6.07 & 6.09 \\
$\mu_{\exp }\left(\mu_{\mathrm{B}}\right)$ & 6.24 & 6.39 & 6.44 & 6.45 & 6.47 & 6.48
\end{tabular}

transition temperature from AFM to cAFM, noted as $T_{\mathrm{N} 2}$, which is $45 \mathrm{~K}$, as listed in Table 1 . These values agree well with data reported by other researchers. ${ }^{33-36}$

With an increase of $\mathrm{Mn}$ in the samples, the "negative magnetization" in the ZFC curve disappears, as shown in Fig. 6. Similarly to $\mathrm{M} 1\left(\mathrm{EuMnO}_{3}\right)$, two characteristic temperatures, $T_{\mathrm{N} 1}$ and $T_{\mathrm{N} 2}$, can be obtained from the temperature dependence of the magnetic susceptibility in the samples M2 to M6 in ZFC and FC modes, which are listed in Table 1. It is found that with an increase of Mn in the system, the PM to AFM phase transition temperature, $T_{\mathrm{N} 1}$, increases. This means that $\mathrm{Mn}$ is a good dopant to increase $T_{\mathrm{N} 1}$ in $\mathrm{Eu}_{1-x} \mathrm{Mn}_{x} \mathrm{MnO}_{3-\delta}$. A similar phenomenon is also found for $\mathrm{Mn}$ doped $\mathrm{TbMnO}_{3} \cdot{ }^{17}$

The linearity of $\chi^{-1}(T)$ above the temperature $T_{\mathrm{N} 1}$ shown in Fig. $6 \mathrm{~d}-\mathrm{f}$ suggests that the reciprocal magnetic susceptibility follows the Curie-Weiss (CW) law, $\chi=C /(T-\theta)$, where $\chi$ is the magnetic susceptibility of the paramagnetic phase, $C$ is the Curie constant, $T$ is the temperature, and $\theta$ is the Weiss constant. The corresponding Curie constants $C$, Weiss constants $\theta$ and effective paramagnetic moments are obtained and presented in Table 1 . The effective magnetic moment calculated from the Curie constant $C$ increases with an increase in $\mathrm{Mn}$ in the sample, and agrees well with the expected value under the supposition ${ }^{37}$ that $\mu_{\text {eff }}^{2}=(1+x) \mu_{\text {eff }}^{2}\left(\mathrm{Mn}^{3+}\right)+(1-x)$ $\mu_{\text {eff }}^{2}\left(\mathrm{Eu}^{3+}\right)$, with $\mu\left(\mathrm{Mn}^{3+}\right)=4.90 \mu_{\mathrm{B}}$, and $\mu\left(\mathrm{Eu}^{3+}\right)=3.40 \mu_{\mathrm{B}}$. The obtained Weiss constant $\theta$ is negative, which indicates that the magnetic interaction is antiferromagnetic in nature.

The magnetic hysteresis loops at selected temperatures have been measured and typical data are shown in Fig. 7. The magnetic hysteresis loops show a clear butterfly shape at $10 \mathrm{~K}$, indicating that the samples are metamagnetic at this temperature. The maximum magnetization value, at $H=7 \mathrm{~T}$ at $10 \mathrm{~K}$, increases from 12.8 to $38.9 \mathrm{emu} \mathrm{g}^{-1}$ with an increase in $\mathrm{Mn}$ content from 0.025 to 0.125 , indicating that doping of $\mathrm{Mn}$ at the Eu site makes $\mathrm{Eu}_{1-x} \mathrm{Mn}_{x} \mathrm{MnO}_{3}$ easier to magnetize, which is similar to $\mathrm{Eu}_{1-x} \mathrm{Y}_{x} \mathrm{MnO}_{3}$ (ref. 4) and $\mathrm{Eu}_{1-x} \mathrm{Sr}_{x} \mathrm{MnO}_{3}{ }^{38}$ 

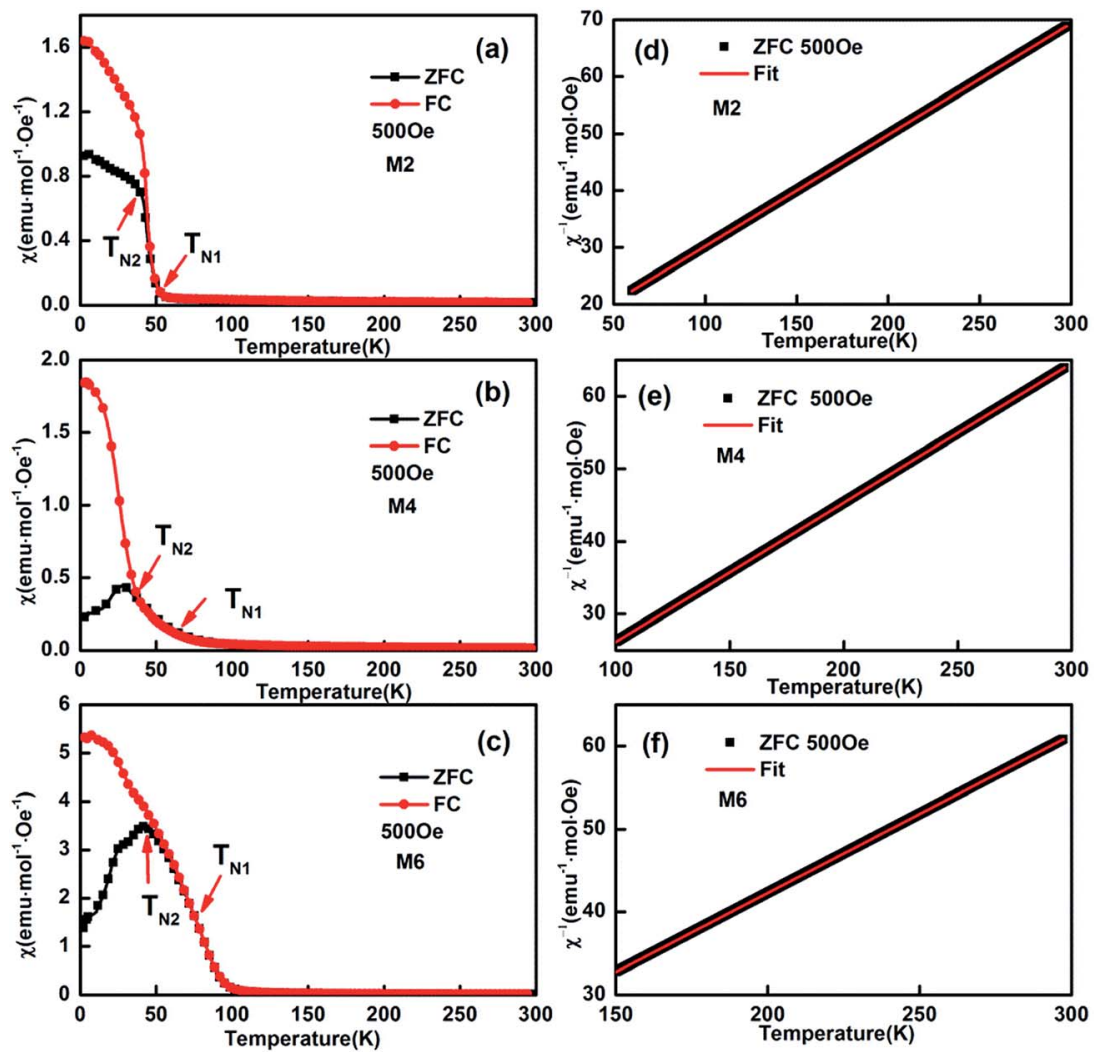

Fig. 6 Typical temperature dependence of the magnetization of $\left(\mathrm{Eu}_{1-x} \mathrm{Mn}_{\chi}\right) \mathrm{MnO}_{3-\delta}: \chi-T$ and $\chi^{-1}-T$ curves for $\mathrm{M} 2$ (a and d), $\mathrm{M} 4(\mathrm{~b}$ and $\mathrm{e})$, and $\mathrm{M} 6$ (c and f), respectively.
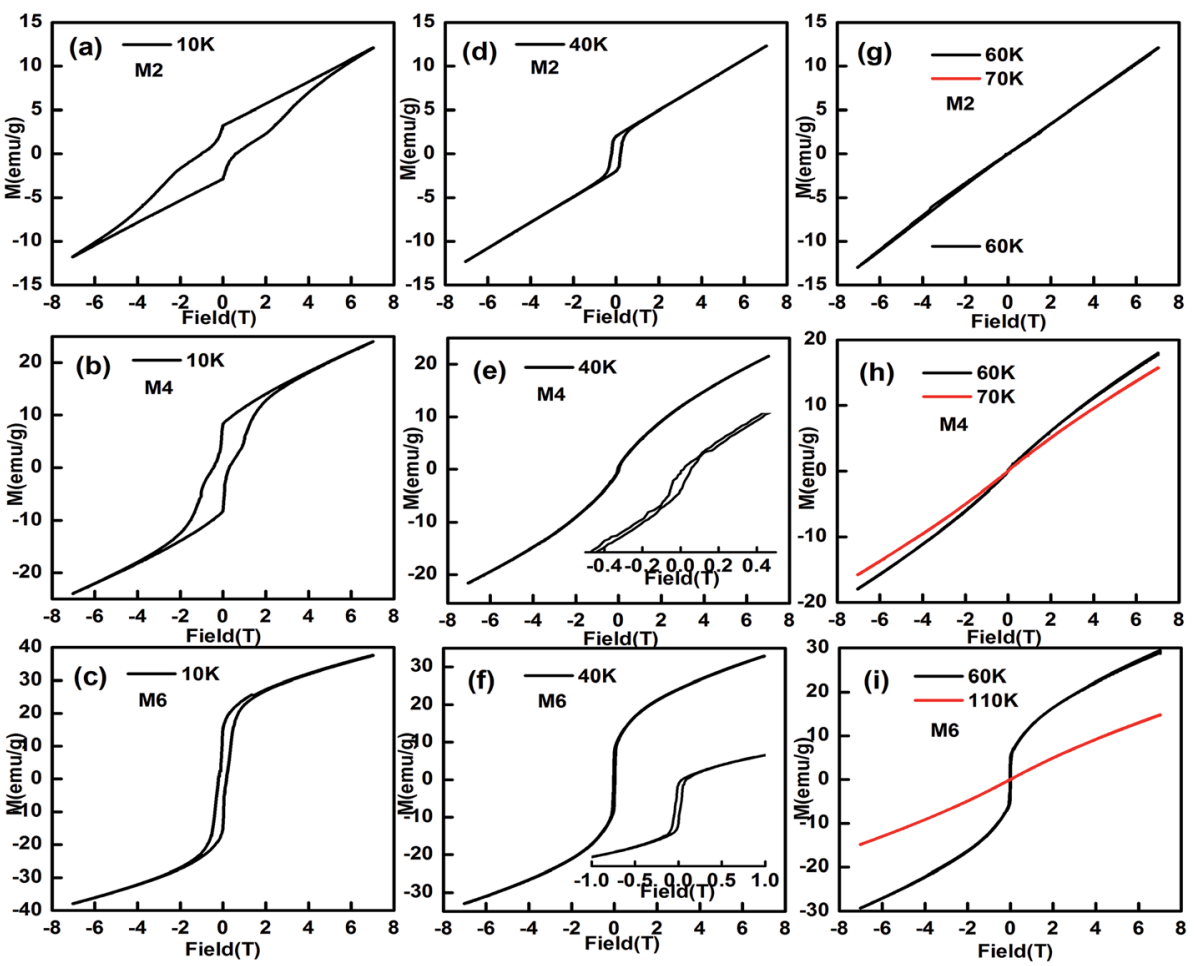

Fig. 7 The magnetic hysteresis loops for $M 2, M 4$ and $M 6\left(\left(E u_{1-x} M_{x}\right) M n O_{3-\delta}, x=0.025(a, d, g), 0.075(b\right.$, e, h), and $0.125(c, f, i))$ at selected temperatures. 


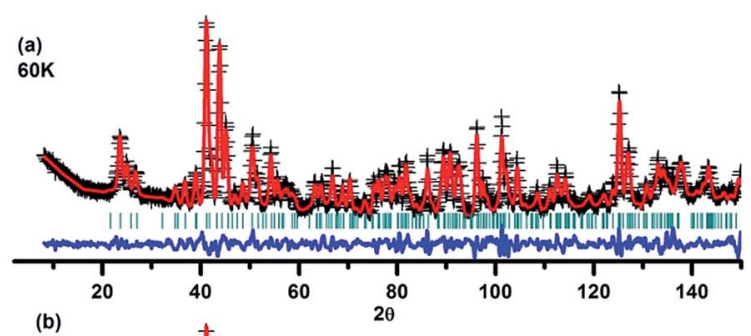

(c)
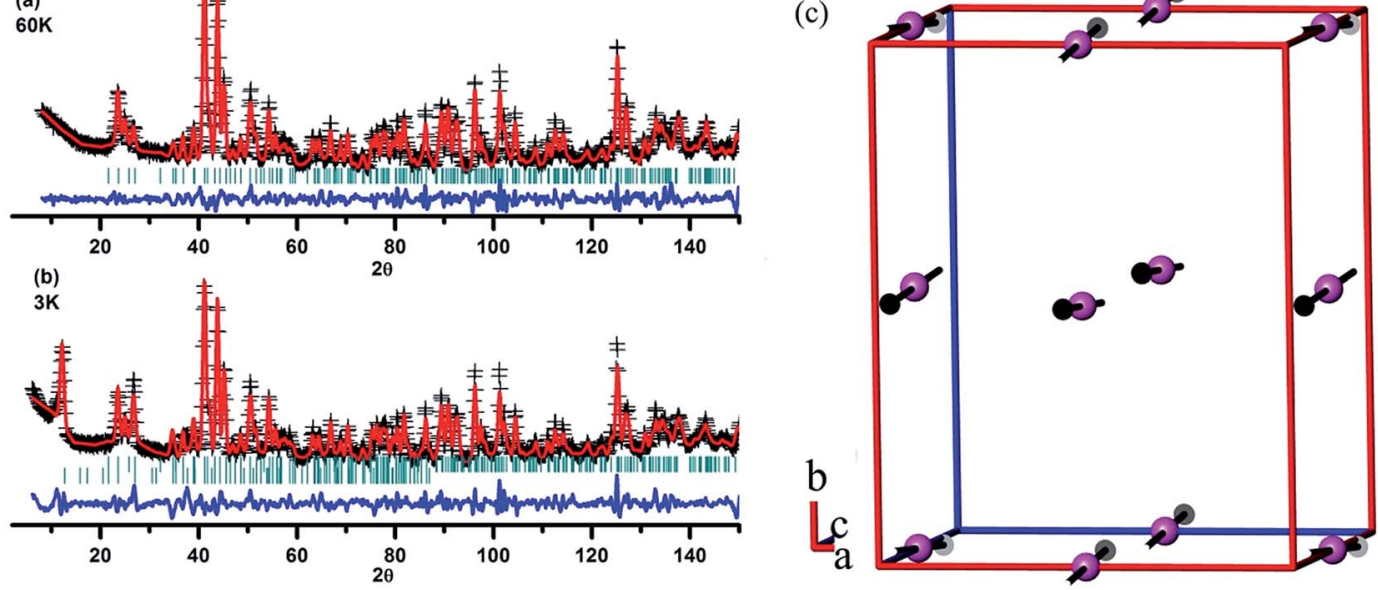

Fig. 8 Rietveld plots of the neutron diffraction data from ${ }^{153} \mathrm{EuMnO}_{3}$ at $60 \mathrm{~K}$ (a) and $3 \mathrm{~K}$ (b), and the magnetic structure of ${ }^{153} \mathrm{EuMnO}_{3}$ at $3 \mathrm{~K}$ (c).

When the temperature increases, the butterfly shape of the $M-H$ curve changes to a normal shape, as shown in Fig. $7 \mathrm{~d}-\mathrm{f}$, which indicates that the samples become canted antiferromagnetic, rather than metamagnetic. At $60 \mathrm{~K}$, a straight line is observed for M2 and M3, which agrees well with the finding that the PM to AFM phase transition temperature $T_{\mathrm{N} 1}$ for $\mathrm{M} 2$ and $\mathrm{M} 3$ is lower than $60 \mathrm{~K}$, as listed in Table 1. But for M4, M5, and M6, the $M-H$ curves are not straight lines at $60 \mathrm{~K}$.

\section{Neutron diffraction of ${ }^{153} \mathrm{EuMnO}_{3}$}

As mentioned previously, ${ }^{32,39}$ it is hard to get neutron diffraction data for $\mathrm{EuMnO}_{3}$ because the neutrons can be absorbed by Eu. Therefore, the magnetic structure of $\mathrm{EuMnO}_{3}$ has not been solved until now, although T. Goto et al. ${ }^{34}$ have predicted that it has a phase transition from PM to ICAFM (incommensurate antiferromagnetic) at $\sim 50 \mathrm{~K}$, and a further transition from ICAFM to cAAFM (canted A-type antiferromagnetic) ordering at $\sim 44 \mathrm{~K}$. It has been reported that neutron diffraction data can be obtained for

${ }^{153} \mathrm{EuMnO}_{3},{ }^{39}$ where only data from around room temperature has been presented, which confirms that ${ }^{153} \mathrm{EuMnO}_{3}$ crystallizes in the space group Pnma. Therefore, ${ }^{153} \mathrm{EuMnO}_{3}$ has been synthesized in our lab and sent away for neutron diffraction data collection at 60 and $3 \mathrm{~K}$. As shown in Fig. 8a, the neutron diffraction data for ${ }^{153} \mathrm{EuMnO}_{3}$ at $60 \mathrm{~K}$ can be refined well using the space group Pnma with the parameters listed in Table 2, which may indicate that the structure of ${ }^{153} \mathrm{EuMnO}_{3}$ does not change between $300 \mathrm{~K}$ and $60 \mathrm{~K}$. However, new diffraction peaks are found in the neutron data from ${ }^{153} \mathrm{EuMnO}_{3}$ at $3 \mathrm{~K}$, which can be attributed to the A-type ${ }^{40}$ magnetic ordering of $\mathrm{Mn}$ in ${ }^{153} \mathrm{EuMnO}_{3}$, as shown in Fig. 8c with the refinement parameters listed in Table 2. In the first work on the magnetic structure of $\mathrm{Mn}$ in the doped perovskite $\mathrm{LaMnO}_{3}$, E. O. Wollan et al. ${ }^{40}$ established a note system of A, B, C, D, E, F, and G type to note the different possible magnetic structures of Mn. Specially, A-type magnetic ordering means that the magnetic moment arrangement of $\mathrm{Mn}$ is similar to that shown in Fig. 8c. That is, the magnetic moments of the four-close-neighboring $\mathrm{Mn}$ in the first and the second layer are inversed. As shown in Fig. 8c, the moment of $\mathrm{Mn}$ in the first layer directs to the positive $c$-axis, while the moment of $\mathrm{Mn}$ in the

Table 2 Rietveld refinement details for the neutron diffraction data from ${ }^{153} \mathrm{EuMnO}_{3}$ at $60 \mathrm{~K}$ and $3 \mathrm{~K}$

\begin{tabular}{|c|c|c|}
\hline & $60 \mathrm{~K}$ & $3 \mathrm{~K}$ \\
\hline Phase 1 & Nuclear phase & Nuclear phase \\
\hline Space group & Pnma & Pnma \\
\hline Lattice parameters $(\AA)$ & $a=5.8217(2), b=7.2138(3), c=5.3242(8)$ & $a=5.8183(2), b=7.2082(3), c=5.3269(2)$ \\
\hline Atom & $x, y, z$ & $x, y, z$ \\
\hline $\mathrm{Eu}$ & $0.0787(3), 0.2500,0.9844(3)$ & $0.0800(3), 0.2500,0.9845(3)$ \\
\hline Mn & $0.0000,0.0000,0.5000$ & $0.0000,0.0000,0.5000$ \\
\hline O1 & $0.4722(3), 0.2500,0.0957(3)$ & $0.4678(3), 0.2500,0.0974(3)$ \\
\hline $\mathrm{O} 2$ & $0.3236(3), 0.0462(3), 0.7063(3)$ & $0.3249(3), 0.0478(3), 0.7066(3)$ \\
\hline Phase 2 & & Magnetic phase \\
\hline Space group & & Pnma1' \\
\hline Lattice parameters $(\AA)$ & & $a=5.8183(2), b=7.2082(3), c=5.3269(2)$ \\
\hline Atom & & $(x, y, z) /\left(\mathbf{M}_{x}, \mathbf{M}_{y}, \mathbf{M}_{z}\right)$ \\
\hline Mn & & $(0.0000,0.0000,0.5000) /(-0.554,0.190,2.868)$ \\
\hline$R$ factor ${ }^{a}$ & $R_{\mathrm{wp}}=0.033, R_{\mathrm{p}}=0.026$ & $R_{\mathrm{wp}}=0.041, R_{\mathrm{p}}=0.031$ \\
\hline
\end{tabular}

${ }^{a} R_{\mathrm{p}}$ is $\operatorname{sum}\left(\left|I_{0}-I_{\mathrm{C}}\right|\right) / \operatorname{sum}\left(I_{0}\right)$, and $R_{\mathrm{wp}}$ is the weighted $R$ factor for the neutron diffraction data. 
second layer directs to the negative $c$-axis. Our results confirm the prediction of a cAAFM phase for $\mathrm{EuMnO}_{3}$ by $\mathrm{T}$. Goto et al. ${ }^{34}$ More careful studies are planned to confirm the ICAFM phase for ${ }^{153} \mathrm{EuMnO}_{3}$.

\section{Conclusions}

Solid solution $\mathrm{Eu}_{1-x} \mathrm{Mn}_{x} \mathrm{MnO}_{3-\delta}$ has been synthesized using a conventional solid state method at $1200{ }^{\circ} \mathrm{C}$ under air. The powder X-ray diffraction and selected area electron diffraction data confirm that all samples crystallize in the space group Pnma at room temperature. The range of $x$ for the solid solution obtained in the present case is assessed to be $0 \leq x \leq 0.126$. With the doping of $\mathrm{Mn}$ in the Eu site, the paramagnetic to antiferromagnetic phase transition moves to a higher temperature. In addition, the neutron diffraction data from ${ }^{153} \mathrm{EuMnO}_{3}$ at $3 \mathrm{~K}$ confirmed that the magnetic structure of $\mathrm{EuMnO}_{3}$ at low temperatures is canted A-type antiferromagnetic.

\section{Acknowledgements}

This work is supported by the National Key Basic Research Project of China (2010CB833103), and the National Natural Science Foundation of China (Grants 21271014, 11275012). We thank Dr M. Avdeev for assistance in collecting the neutron power diffraction data at the OPAL facility.

\section{References}

1 T. Kimura, T. Goto, H. Shintani, K. Ishizaka, T. Arima and Y. Tokura, Nature, 2003, 426, 55.

2 M. Fiebig, T. Lottermoser, D. Fröhlich, A. V. Goltsev and R. V. Pisarev, Nature, 2002, 419, 818.

3 T. Lottermoser, T. Lonkai, U. Amann, D. Hohlwein, J. Ihringer and M. Fiebig, Nature, 2004, 430, 541.

4 J. Hemberger, F. Schrettle, A. Pimenov, P. Lunkenheimer, V. Y. Ivanov, A. A. Mukhin, A. M. Balbashov and A. Loidl, Phys. Rev. B: Condens. Matter Mater. Phys., 2007, 75, 035118.

5 V. Cuartero, J. Blasco, J. García, G. Subías, C. Ritter and J. Alberto Rodríguez-Velamazán, Phys. Rev. B: Condens. Matter Mater. Phys., 2010, 81, 224117.

6 D. O'Flynn, C. V. Tomy, M. R. Lees, A. Daoud-Aladine and G. Balakrishnan, Phys. Rev. B: Condens. Matter Mater. Phys., 2011, 83, 174426.

7 H. D. Zhou, J. C. Denyszyn and J. B. Goodenough, Phys. Rev. B: Condens. Matter Mater. Phys., 2005, 72, 224401.

8 P. P. Rout, S. K. Pradhan and B. K. Roul, Ceram. Int., 2014, 40, 9647.

9 A. Nandy and S. K. Pradhan, Dalton Trans., 2015, 44, 17229. 10 A. Astudillo, J. Izquierdo, F. J. Bonilla, G. Bolaños and O. Morán, IEEE Trans. Magn., 2013, 49, 4590.

11 E. Pollert and Z. Jirak, J. Solid State Chem., 1980, 35, 262.

12 G. Lescano, F. M. Figueiredo, F. M. B. Marques and J. Schmidt, J. Eur. Ceram. Soc., 2001, 21, 2037.

13 I. Gélard, N. Jehanathan, H. Roussel, S. Gariglio, O. I. Lebedev, G. Van Tendeloo and C. Dubourdieu, Chem. Mater., 2011, 23, 1232.
14 A. N. Ulyanov, N. E. Pismenova, D. S. Yang, V. N. Krivoruchko and G. G. Levchenko, J. Alloys Compd., 2013, 550, 124.

15 R. Wang, C. X. Yang, M. Fan, M. M. Wu, C. H. Wang, X. H. Yu, J. L. Zhu, J. R. Zhang, G. B. Li, Q. Z. Huang, D. F. Chen, T. N. Jin, T. Kamiyama, F. H. Liao and J. H. Lin, J. Alloys Compd., 2013, 554, 385.

16 H. Zhang, R. Flacau, J. L. Sun, G. B. Li, F. H. Liao and J. H. Lin, Inorg. Chem., 2014, 53, 4535.

17 H. Zhang, R. Flacau, X. Du, P. Manuel, J. Z. Cong, Y. Sun, J. L. Sun, S. H. Yang, G. B. Li, F. H. Liao and J. H. Lin, ChemPhysChem, 2016, 17, 1098.

18 O. M. Fedorova, V. F. Balakirev and Yu. V. Golikov, Inorg. Mater., 2007, 43, 994.

19 H. M. Rietveld, J. Appl. Crystallogr., 1969, 2, 65.

20 B. H. Toby, J. Appl. Crystallogr., 2001, 34, 210.

21 N. V. Kasper and I. O. Troyanchuk, J. Phys. Chem. Solids, 1996, 57, 1601.

22 G. B. Li, S. X. Liu, F. H. Liao, S. J. Tian, X. P. Jing, J. H. Lin, Y. Uesu, K. Kohn, K. Saitoh, M. Terauchi, N. L. Di and Z. H. Cheng, J. Solid State Chem., 2004, 177, 1695.

23 H. Wang, C. H. Wang, G. B. Li, T. N. Jin, F. H. Liao and J. H. Lin, Inorg. Chem., 2010, 49, 5262.

24 H. Wang, C. X. Yang, J. Lu, M. M. Wu, J. Su, K. Li, J. R. Zhang, G. B. Li, T. N. Jin, T. Kamiyama, F. H. Liao, J. H. Lin and Y. C. Wu, Inorg. Chem., 2013, 52, 2388.

25 L. Vegard, Z. Phys., 1921, 5, 17.

26 L. Vegard, Z. Kristallogr., 1928, 67, 239.

27 T. S. Chan, R. S. Liu, C. C. Yang, W. H. Li, Y. H. Lien, C. Y. Huang and J. F. Lee, J. Phys. Chem. B, 2007, 111, 2262. 28 Y. U. wamino, T. Ishizuka and H. Yamatera, J. Electron Spectrosc. Relat. Phenom., 1984, 34, 67.

29 D. F. Mullica, C. K. C. Lok, H. O. Perkins, G. A. Benesh and V. Young, J. Electron Spectrosc. Relat. Phenom., 1995, 71, 1.

$30 \mathrm{M}$. Oku, K. Hirokawa and S. Ikeda, J. Electron Spectrosc. Relat. Phenom., 1975, 7, 465.

31 V. Di Castro and G. Polzonetti, J. Electron Spectrosc. Relat. Phenom., 1989, 48, 117.

32 A. M. Yang, Y. H. Sheng, M. A. Farid, H. Zhang, X. H. Lin, G. B. Li, L. J. Liu, F. H. Liao and J. H. Lin, RSC Adv., 2016, 6, 13928.

33 I. O. Troyanchuk, N. V. Samsonenko, N. V. Kasper, H. Szymczak and A. Nabialek, Phys. Status Solidi A, 1997, 160, 195.

34 T. Goto, T. Kimura, G. Lawes, A. P. Ramirez and Y. Tokura, Phys. Rev. Lett., 2004, 92, 257201.

35 W. S. Ferreira, J. A. Moreira, A. Almeida, M. R. Chaves, J. P. Araújo, J. B. Oliveira, J. M. M. Da Silva, M. A. Sá, T. M. Mendonça, P. S. Carvalho, J. Kreisel, J. L. Ribeiro, L. G. Vieira, P. B. Tavares and S. Mendonça, Phys. Rev. B: Condens. Matter Mater. Phys., 2009, 79, 054303.

36 R. Das and P. Poddar, RSC Adv., 2014, 4, 10614.

37 J. H. Van Vleck, J. Appl. Phys., 1968, 39, 365.

38 Y. Tadokoro, Y. J. Shan, T. Nakamura and S. Nakamura, Solid State Ionics, 1998, 108, 261.

39 B. Dabrowski, S. Kolensnik, A. Baszcuk, O. Chmaissem, T. Maxwell and J. Mais, J. Solid State Chem., 2005, 178, 629. 40 E. O. Wollan and W. C. Koehler, Phys. Rev., 1955, 100, 545. 